\title{
Public Information and Perception of the Environmental Risk about the Works for the City High Speed Railroad Underpass in Florence,
} Italy

\author{
Bruno Bertaccini
}

Dept. of Statistics, Informatics, Applications “G. Parenti” - University of Florence

Giulia Biagi

Dept. of Statistics, Informatics, Applications “G. Parenti” - University of Florence

Received 15 March 2018; received in revised form 16 November 2015; accepted 10 December 2018

\begin{abstract}
The Florence railway node plays a strategic role in the panorama of the Italian transport system because of its geographical central position. To avoid excessive traffic density and to separate low and fast tracks, a railway city-bypass of $9 \mathrm{Km}$ (7 of which underground) and a new station for the high-speed railway have been planned. Because of the political implications of this decision, it was designed a large opinion poll to understand the current level of information of the citizens on the planned works and to measure their perception of the environmental risks associated with. Given the number of people interviewed, the opinion poll conducted in Florence surely ranks among the most important surveys conducted in Italy on this topic and contributes new insights on the complex links between populations and the environment.
\end{abstract}

Key words: High-speed railways lines, environmental damages, risk perception, opinion poll, mixed survey techniques

\section{JEL Classification: Q56, Q58, R58}




\section{Introduction}

In the last 20 years, the European Union has allocated many resources in restructuring the European railways transport network with the aim of strengthening it with respect to the other transport modalities. The Trans-European Networks (TEN) is a railways network project regarding all the major lines that run through the nations belonging to the European Union. The Community guidelines for the development of the trans-European transport networks have been defined in Decision No. 1692/96/EC, as last amended by Decision n. 884/2004/EC which identifies thirty priority projects of European interest to be accomplished by 2020 . Fourteen projects were already identified in the original text in accordance with the guidelines of the European Council in Essen in 1994; sixteen new projects were added in Decision n. 884/2004/EC to take account of the accession of new Member States. During the TEN-T (Trans-European Transport Networks) days held in Tallinn (Estonia - from $16^{\text {th }}$ to $18^{\text {th }}$ of October, 2013), the European Commission consolidated his railways transport infrastructure policy with the aim of bridging the gaps between the transport networks of the Member States, removing the bottlenecks hampering the smooth functioning of the internal market and, more in general, helping the economy in its recovery and growth. The slogan was "transform a patchwork in a network"; $€ 26$ billion to be spent before 2020 were allocated to this ambitious project.

The Scandinavian - Mediterranean TEN-T Corridor is the main corridor on the North-South axis. It is identified as one of the most strategic corridors for the growth of the European economy that should connect the major urban centers of Germany and Italy to Scandinavia and Mediterranean areas. Limiting our comments to the Italian section of the corridor, it is worth mentioning that the high-speed railway line between Milan and Naples became fully operational with the completion of the Bologna Florence section at the end of 2009. The travel time between Milan and Rome was reduced from 5 hours to 2 hours and 45 minutes and the volume of passengers between Milan and Naples increased by about 25\%, reaching 20 million passengers in 2010. 
Florence plays a strategic role in the panorama of Italian railway system because of its geographical position representing the central nodes of the north-south ridge, the Tyrrhenian line and the Florence - Faenza line toward the Adriatic Sea. In addition, Florence is also the center of gravity of the regional and metropolitan traffic. This causes a traffic density close to saturation. In order to increase the overall capacity of the node and improve the compatibility between the different types of local, freight and long-distance traffic, major upgrade works were planned at the beginning of the $70 \mathrm{~s}$. It was only from the 90s, with the planning of the Milan - Naples high speed railway line, that definitive solutions for the reorganization of the Florentine node were decided. Unfortunately, Florence is still the only point of the Milan-Naples line where highspeed trains do not pass on dedicated rails; this obviously causes the mentioned overload on this route, generating delays and preventing an expansion of the service.

The Protocol of agreement of 24 April '97 between local authorities, the Ministry of Transport and the Italian State Railways ${ }^{1}$ preannounced the so-called "cura del ferro" ("iron treatment") for the metropolitan area, with the enhancement of the existing railway lines, the consolidation of the Faenza line and the creation of new stops for the urban trains. Later, the planning of the interventions and the priorities underwent several updates: the agreement of August 3, 2011 between the Italian Railway Network (RFI the company that is nowadays in charge of the management of the Italian Railroad infrastructures), the Municipality of Florence, the Province of Florence and the Tuscany Region gave preference to aspects related to urban mobility. The main actions planned in the agreement were the construction of the Florence railway bypass and the related new high-speed railway station in the area called "ex-Macelli" (international tender won by Norman Foster studio \& co. and by the engineering firm Ove Arup \& co.). The Florence railway bypass is an urban crossing designed exclusively for the high-speed traffic of about 9 kilometers, 7 of which underground. It starts at the Florence Castello station, where the high speed line Bologna-Florence ends, goes underground near the Rifredi station (northern side of the city of Florence) and rises to the surface at the "Campo di Marte" station (southern side of the city). The work should bring several benefits to the urban and metropolitan area: reduction of noise and visual impact of the trains, clear separation between urban and domestic traffic to achieve more punctuality

\footnotetext{
${ }^{1}$ http://www.rfi.it/cms-file/allegati/rfi/documenti/19970424ProtocolloIntesaCastelloNodoFirenze.pdf
} 
of regional trains, greater potential of the railway hub and increased operating speed. For the implementation of the work, RFI and the city administration agreed to a series of measures aimed at integrating the new railway infrastructure with the urban transportation system (construction of new tram lines, hydraulic adjustment of the Mugnone and Terzolle creeks, new railway underpasses, new parking areas, etc.).

The project started in 1995 and had a complex procedure with many local agencies involved and requiring permissions and approval by many authorities. In recent years, it also met a strong opposition from some citizens' committees, concerned about the cost of the work compared to the actual benefits for the community and the environmental impact of the underpass. The construction of the tunnel was stopped prematurely and, so far, the Ministry of the Environment has not yet given the permits necessary for the disposal of the excavated soils and stones.

A Committee, the "Guarantee Committee for Information and Communication of the Florence High-Speed Node" (composed by independent members designated by the Municipality, the Province of Florence and the Tuscany Region), has been specially established in order to implement a timely and accurate plan of communication and information on the work. The Committee, among the first steps taken, considered it essential to commission a local demoscopic survey to understand the state of information of Florentine citizens about the project underway. In order to plan information campaigns aimed at preventing unjustified fears, the survey sought in particular to assess the level of concern of citizenship on some aspects related to the implementation phases of the work and to know the opinion of the population about the opportunities, in terms of cost-benefit ratio, offered by its realization. 2446 interviews were carried out; the survey was conducted in May and June of 2012, i.e. before the scheduled departure of the drilling activities. Given the large number of people interviewed and the methodologies employed, this opinion poll surely ranks among the most important surveys conducted in Italy on this topic. The scientific dissemination of the survey results has been intentionally delayed in order to ensure to the urban policy an adequate period of reflection on the most appropriate ways to use research outcomes, given the ongoing political debates and the extreme relevance of the issues being investigated. 
We believe that this type of investigation can facilitate the relationship between Public Administrations and Citizens. The nature of the survey (i.e. based on sampling techniques) is not under discussion (especially when it is important to return timely information to the decision makers). But, due to its nature, it is important that the survey methodology maximizes the participation rate, reducing all the possible distortions related to the non-response issue. The methodology we adopted in this paper is easily replicable and guarantees a very satisfactory participation rates in relation to the survey themes and to the worsening trend highlighted by the average rate of participation in opinion polls recorded over the last 15 years.

In the following paragraphs: to understand how the population's concerns arise, also in relation to the environmental effects of major public works, a brief overview of the literature on perception of risk is firstly presented; then some of the main events that in this sense have influenced recent Italian history are mentioned; it is therefore motivated the need to find appropriate communication policies aimed at preventing unjustified dreads in the population. Finally, the survey methodology and an explanation to the main results of the poll are then illustrated.

\section{Citizens' Risk Perception about Environmental Damages}

Currently, the word "risk" is used to express danger, threat, hazard and harm; today is hence no longer associated, as in the Enlightenment era, also to positive outcomes but it has only negative connotations (Lupton, 2003). The cultural theory of risk was originally proposed by Mary Douglas (Douglas, 1992; Douglas and Wildavsky, 1982), who argued that the perception, recognition and management of risk are intimately connected and filtered by the specific culture and social organization in which people act. The perception of risk is a cognitive process that assesses the immediate and future consequences of a particular event or action; the implications of these consequences develop not only at an individual level, on an emotional and subjective sphere, but mostly at the collective level, on a rational and objective sphere as a culturally standardized response (Douglas, 1992; Slovic, 2001). 
According to the sociologist Luhmann, one of the main reasons why the concept of "perceived risk" has become relevant in contemporary world lies in the fact that "the future of our society depends increasingly on social decisions". While science and technology, with their almost limitless possibilities, are supplanting nature, on the other hand also give us a sense of distrust that leads us to believe that any excess of progress may bring destructive effects. The fear that things can go awry is quickly growing, and with it the amount of risk that is attributed to policies that involve the environment in which people live (Ruggiero, 2000). The environmental risks have become an important ground to measure the ability to govern a territory and in which economic factors intersect with the scientific knowledge, with the available technical solutions and, most importantly, with the beliefs, the expectations and the fears of the citizens. With regard to the environmental risks, the already existing gap between technicians and the population is emphasized, as the population generally disagrees with the "objective" estimates of the impact and the risk that the technicians propose.

The quantitative estimation approach "usually" ignores non-quantifiable aspects, such as the indirect economic losses, the political and social damages and the effects on long-term health (carcinogenicity, mutagenicity, etc.), particularly felt by the population. Furthermore, in the calculation of the probability of the occurrence of an accident that involves consequences for the environment (and hence for the human being), the common person tends to fear an occurrence of it even if it is excluded on the basis of statistical reasoning. On the contrary, the population would accept, on a precautionary way, a risk hypothesis (which is not statistically significant) which then is actually false.

The statistical significance of the results depends on the choice of a threshold that the involved population often does not share. Finally, the acceptability of the final results of an analysis, presented in statistical form, is still subject to perception. Normally, low probabilistic values, typical of the objective analysis of risk, are very difficult to interpret by most people that tend to accept the technicians' conclusion about an accident with high probability and low consequences, refusing the ones about an accident with low probability and high consequences, although both events, according to the expected utility theory, have the same expected social cost (Cossu, Gadia and Luria, 2013). 


\section{Mugello, "Variante di Valico" and Susa Valley}

Environmental risks have become a significant issue for the community, for health, for economic and social growth. As saw above, the project for the completion of the high-speed railway network in Italy is of crucial importance for a quick connection of the main Italian cities. However, a major work is never with zero impact on the environment and the balance between costs and benefits could often be negative.

In March 2014, the Court of Appeals of Florence convicted the top management of the CAVET Consortium (Consortium High Speed Emilia Tuscany, responsible for the direction of the works of the high-speed line Florence - Bologna) for environmental crimes. The environmental crimes attributed to them were: unlawful disposal of excavated debris that are still releasing pollutants; desiccation and depletion of 81 waterways; desiccation and depletion of 37 springs; desiccation and depletion of approximately 30 wells; desiccation and depletion of 5 five aqueducts; non-reclamation of polluted streams.

The excavation works for the implementation of the $73.3 \mathrm{~km}$ tunnel required for the conclusion of the Florence-Bologna High Speed railway resulted in a reduction, often a completely elimination, of the flow rates of many wells and springs, some of which fed important aqueducts ("Scarperia", "Luco di Mugello", "Grezzano"), with the consequence of heavy damages to agriculture and livestock raising and irreversible damages to the hydrophil fauna and vegetation. The entire hydrogeological balance of the Mugello region has been shocked. The decrease of water resulted in a heavy fallout of the mountain ecosystem, forcing many agro-livestock farms to close. Just to cite some examples of such worrying situation, there are areas in the Mugello region where water has to be brought up from a lower level using a lot of electricity while, in the past, the same water was got for gravity; moreover, the water shows a decline in quality and often necessitate costly operations of purifications. 
In recent years the Mugello region was also interested by the implementation of the so-called "Variante di Valico" which is a stretch of a highway between Barberino di Mugello and Sasso Marconi (65.8 km of total length). The major work was decided by the Prodi government in 1996 as a high priority work. It is divided into two sections: "Sasso Marconi - La Quercia" and "La Quercia - Barberino". The work of the first stretch started in 2002 and ended in July 2006. The second stretch was supposed to end in 2015, but a series of technical and environmental problems delayed the completion of it. The mountain push first reached the Val di Sambro tunnel bringing it off-axis with respect to the nearby roadway. With the awareness of the risks related to the implementation of the new hole in the rock, ultra-modern systems equipped to block immediately the eventual collapse of the earth were used for the implementation of the new tunnel. Unfortunately, in spite of the expensive measures taken, the casing of the tunnel roof has fallen out for part of the tunnel length (about 250 metres) and for several time it was has not been safe to open the tunnel to the traffic.

In recent years, always relating to the high-speed railway works, great emphasis was given to the riots in the Susa Valley (in the province of Turin) where the construction of the Lyon-Turin high-speed railway line is underway, an integral part of the TEN-T corridor 6 Lyon-Budapest. Citizens see the construction of this line as a threat to both their health, since the extraction of rocks is characterized by the presence of hazardous materials (asbestos and uranium), and to the maintenance of the valley rivers. The construction of the main tunnel between France and Italy would dug out an enormous amount of material that, it is estimated, could form a tower 750 meters high with a base of 100 square meters (AA.VV., 2002). The project would create an indirect flow of debris and stones containing dangerous substances that must be transported and handled at local and national level. Studies of the Geo-technological Center of the University of Siena (Maccheri, Monaci Naldini and Antompaoli, 2003) have estimated that more than one million cubic meters of material containing asbestos would be extracted from the tunnel that should pass under Musinè mount: although asbestos can safely be treated, these procedures would considerably increase the costs and the duration of the project and the risks would not be totally eliminated. The use of mines and other excavation activities could alter dangerously the underground waterways, vital for the springs, and dry completely part of the mountain areas, as happened in the 
Mugello region. Furthermore, even the morphology and the landscape features would be changed by the planned works. The areas required for the construction sites and storage of the extracted material will result in the loss of arable land, meadows and forests. This threat raises the question of the lack of assessment of landscape impact currently absent from any decision-making process.

Furthermore, the projects for carrying out the new lines of the high-speed railway often require the construction of new stations to separate slow (local passengers and goods) from fast traffic. The drilling works needed for the construction of the new station in Bologna, during the years 2008/2009, have compromised the static of some public and private buildings.

\section{The Importance of Communication Policies}

The processes of diffusion of fears related to risk perception occur spontaneously and continuously. It is important, therefore, to consider risk communication as a process of public interest, which should share conditions and modalities, adequate to be effectively carried out, starting from the trust between all the parties involved. These, however, although in theory have the same rights to be informed and to express opinions, do not have the same communicative force. Risk communication is therefore defined as "the exchange of information and risk assessments among experts, public authorities, media, special interest groups and citizens, aimed at helping in making decisions about the acceptance, the reduction or the avoidance of risk" (Leiss, 1996) and also "an interactive process of exchange of information and opinions among individuals, groups and institutions, involved in the assessment and management of a risk. People (stakeholders) often with different interests and different roles and different skills and different perceptions..." (Gray and Wiedemann, 1999).

According to Kasperson et al. (1988) mass media are generally the main source of risk information. In this regard, an effect widely studied in literature concerns the social amplification of risk. With social amplification of risk is meant a typical effect of mass communication which tends to increase the importance and the spread of negative 
news rather than positive ones. For this reason, the communication cannot be translated into simple transmission of technical data. It requires the analysis of several parameters so that it can become an effective process, able to act on opinions and behavior errors, modifying them in such a way as to avoid or reduce to a minimum the harmful effects on individuals and environment. It is necessary that the communication focuses on both the transmission of simple, clear and correct information, and especially on the credibility of the sources (scientific research, independent researchers, international experts, the convergence of judgments etc.).

\section{The Survey Design}

The events that occurred both in Mugello and in other parts of our country could presumably have act as a factor influencing public opinion on the construction of highspeed railway work at Florence's node. So that, the Guarantee Committee for Information and Communication of the Florence High-Speed Node has been established with the aim to start a timely and accurate implementation of the communication and information plan on the state of progress of the yards.

The Committee has firstly planned a demoscopic survey on sample basis to test the degree of concern of the citizens about certain aspects related to the implementation phases of the work as well as the opinions on the cost / benefit ratio of the project. The information to achieve the objectives were collected by administering a questionnaire designed also to measure the citizens' levels of information and their perception of risk about health and environment. For such research issues, the designing process of the questionnaire was a key step of the research (Pheland and Reynolds, 1996). The questionnaire was principally defined by the Committee and was refined by us in the formulation of some item. Indeed, poorly formulated questions are likely to induce obvious responses or, in addition, to generate anxiety and / or fears in those people who are not adequately informed (Sidhu, 2005). The questionnaire consisted of 22 items organized in 5 sections: a) socio-demographic characteristics of the respondents; b) level of awareness on the whole project (with questions about the work on the underpass and the new station); c) perception of risk and dreads about possible damages 
to the citizens' health; d) information about political issues; e) need to be periodically updated. The questionnaire was administered to a stratified random sample of adult residents of the city of Florence: a stratification by district of residence ( 5 districts), gender and age group (18 - 35; 36 - 65; over 65 years) was adopted, for a total of 30 strata. The survey was conducted during the months of May and June 2012, at a time when it was expected the start of the works for the implementation of the underpass. The survey was commissioned to VALMON s.r.l., a spin-off participated and supported by the University of Florence.

Since most of the variables under investigation are percentage values (e.g. percentage of people aware of the project, percentage of people who consider it a useful intervention, etc.), it was decided that these values should be estimated with a maximum error of 4 percentage points (with probability 0.95 ). In the simple random sampling this result is achieved with a sample size of approximately 600 statistical units if the percentage value is equal to $50 \%$, that is the worst possible scenario when it is present the maximum variability of the phenomenon; values different than $50 \%$ will give errors smaller than 4 percentage points. In fact, the precision of the estimates increases if the estimated percentages deviate from $50 \%$ and if more efficient sampling designs are adopted (such as the stratified random sampling, adopted in this work, that is one of the most efficient design). As a precautionary measure, to estimate percentages for the entire municipality with the above precision, it was felt that 1,200 interviews was a sample size sufficient to ensure at least 600 answers in all significant questions of the questionnaire (even for those questions that are at greater risk of non-response because of their presence in the final part of the questionnaire or that belong to particular subpaths of the questionnaire).

Given the objectives of the inquiry and considering that the drilling activities for the realization of the High Speed Railroad underpass affect only the part of the municipal area to the right of the Arno river, it was considered that the two macroterritorial aggregations (identified with the names of the Florentine popular tradition: "Di quà d'Arno" and "Oltrarno", Graph 1) could realistically better respond to the information needs of the Municipality. For this reason, it was decided to set the final sample size of at least 2400 interviews, or at least 1200 interviews for each of the two identified macro-area. 
For the variables expressed in percentage values, the sample size allows us to contain the estimation error to around two percentage points (with a probability equal to 0.95 ) if we assume simple random sampling (so below the maximum level of $4 \%$ initially fixed). Therefore, the actual estimation error is almost surely lower due to the particular sampling plan adopted (Cochran, 1977).

Graph 1

\section{Districts of the Municipality of Florence with the superimposition of the new high-speed} railroad line

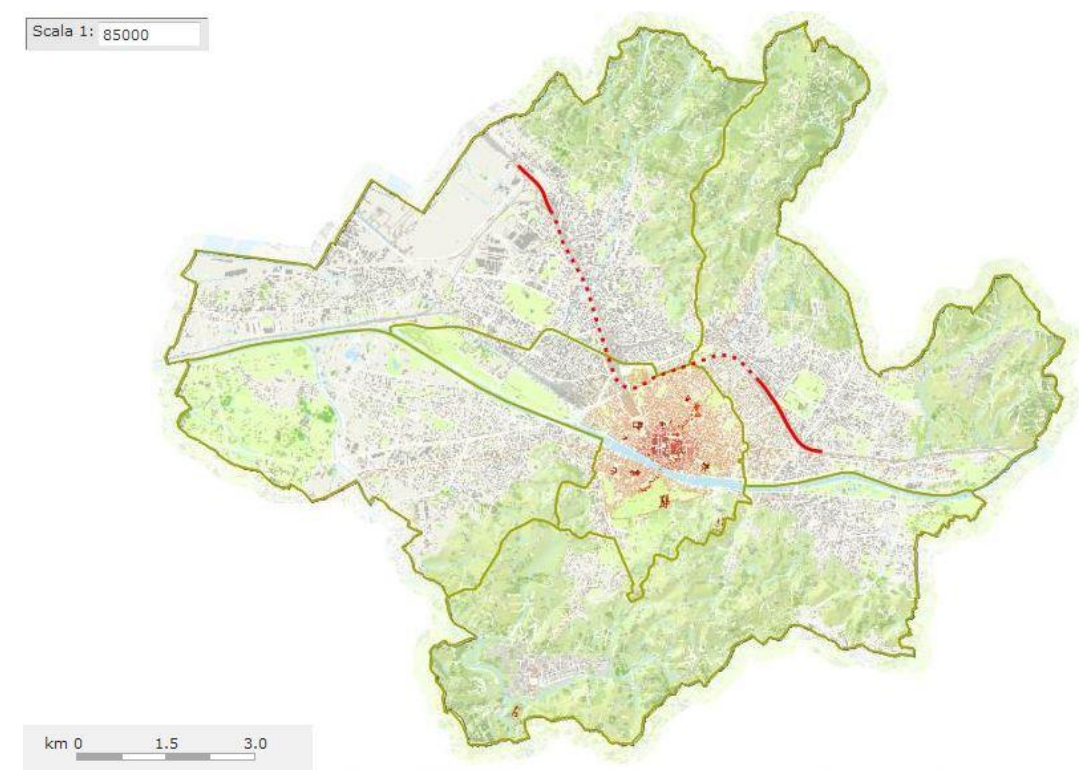

Source: Open GIS of the Municipality of Florence: http://maps.comune.fi.it/tav

Note: the dotted line represents the underpass

Given the number of people interviewed, this opinion poll ranks among the most important surveys conducted in Italy on this topic. A total number of 2,446 interviews were carried out: 1,277 were assisted by computer with CATI (Computer Aided Telephone Interviewing) and the others were directly conducted in the municipal area with a mix method PAPI (Paper Aided Personal Interviewing) - CAWI (Computer Aided Web self-Interviewing), paying particular attention to the residents in areas facing the railroad tracks under construction or in areas directly affected by the drilling activities.

Due to the sensitiveness of the topic of the survey (and its significant political implications at both local and national level), the research has some innovative ideas for 
the survey plan adopted that mixes different techniques of administration of the questionnaire (CATI, CAWI and PAPI), with the general aim to make the "target population", the "sampling frame" and the sampled population as close as possible (Sarndal, Swensson and Wretman, 1992). The "target population" of this survey is represented by all people resident in the city of Florence of major age, stratified as described earlier. Since the "target population" differs from the "sampling frame" due to the "no response" phenomenon, in literature, many contributions suggest the use of mixed interviewing strategies to reduce non-response and improve the quality of data obtained from surveys on sensitive issues (De Leeuw, Hox, and Dillman, 2008; De Bernardo and Curtis, 2013; Kays, Keith, and Broughal, 2013) like the one (politically correlated) promoted by the "Guarantee Committee for Information and Communication of the Florence High-Speed Node".

During the sample design, the possible distortions on the estimation procedures introduced by the method used to draw the sample were evaluated. The first interviews were collected by CATI. The use of CATI methodology allows to interview, nowadays in Italy, only the people who own a landline phone. The diffusion of cell phones in Italy is the highest in Europe and one of the highest in the rest of the world and the number of people that give up landline phones has been increasing in the last few years as well as the number of people that owns more than one mobile phone number (currently, Italy does not have reliable cell phone lists, although some market research companies claim to have them). If people that abandon landline phones are a random sample of the target population there would not be any bias in sampling the remaining population. People who give up landline phones could probably represent the younger population (De Leeuw, 2005) and they are probably more concerned about the use of public resources and more sensitive to environmental issues that are just the issues addressed in the research. Furthermore, in case of strong stratification of the sample, CATI surveys show increasing cost per respondent as the survey progresses, because it is increasingly difficult to identify individuals with certain characteristics, i.e. belonging to particular strata (Bowyer and Rogowski, 2015).

To partially correct the mentioned problems, some interviewers were sent to some meeting points inside the 5 districts of the city (mostly supermarkets, street markets or postal offices), paying particular attention to individuals living in the 
surroundings of the excavation lines. Respondents were initially proposed to choose whether or not to fill in the questionnaire themselves via web. If so, he or she received a ticket with a link to the web page of the questionnaire and personal access keywords. In order to be placed in the correct strata, the interviewee, at the beginning of the web questionnaire, had to specify their own individual characteristics. The questionnaire was instead directly administered to those who preferred the face-to-face interview.

The strategy adopted allows to obtain an overall final response rate of about $22,2 \%$ (Table 1); this rate should to be considered more than satisfactory in view of the topics of the survey, the questionnaire length and, above all, in relation to the worsening trend highlighted by the average rate of participation in opinion polls recorded over the last 15 years, that in recent years is fallen below 10\% (Pew Research Center, 2012).

\section{Survey summary}

Table 1

\begin{tabular}{|l|c|c|c|}
\hline Interview techniques & Contacts & Interviews & Participation rate \\
\hline $\begin{array}{l}\text { CATI (Computer Aided Telephone } \\
\text { Interviewing) }\end{array}$ & 6.383 & 1.277 & $20,0 \%$ \\
\hline $\begin{array}{l}\text { PAPI (Paper Aided Personal } \\
\begin{array}{l}\text { Interviewing) }+ \\
\text { CAWI (Computer Aided Web self- } \\
\text { Interviewing) }\end{array}\end{array}$ & 4.620 & 1.169 & $25,3 \%$ \\
\hline Total & $\mathbf{1 1 . 0 0 3}$ & $\mathbf{2 . 4 4 6}$ & $\mathbf{2 2 , 2 \%}$ \\
\hline
\end{tabular}

Source: Authors

\section{Main Results of the Survey}

In this paragraph, every estimate will be associated with the relative margin of error, always calculated at a 95\% significance level. The percentage of people with some knowledge of the fact that the city of Florence would be affected by the works for the construction of the high speed railroad underpass Milan - Naples was equal to $72.2 \%$. In relation to the sample size, it is estimated that the same proportion in the target population, with a $95 \%$ probability, is between $70.4 \%$ and $73.9 \%$.

As expected, citizen resident in the "Di quà d'Arno" area $(75.8 \% \pm 2.42 \%$, compared to "Oltrarno" with $68.6 \% \pm 2.60 \%$ ), i.e. in Districts affected by excavation works, show higher levels of information compared to the others. Only $50 \% \pm 1,99 \%$ of respondents believe correctly that the project plans a new layout of a railway line, the 
rest or has no idea or thought, wrongly, that the existing railway line will simply be modernized $(18.5 \% \pm 1,55 \%)$.

Only 1444 respondents answered the questions about the exact location of the track line, the rest did not respond and therefore presumably ignores this location; only $33 \% \pm 2,43 \%$ revealed a correct level of information in identifying the stretch of track in the tunnel as located mainly under the existing track. Just over half of respondents $(52.1 \% \pm 1,98 \%)$ is aware of the fact that the project involves the construction of a new station; of these, however, only $75.3 \% \pm 2,37 \%$ were able to correctly locate the new station on the stretch of road between Rifredi and Santa Maria Novella. If the differences by gender and age group are generally not worth mentioning, those relating to the area of residence, although not significant, showed higher percentages of correct information for residents in the areas affected by the works.

Citizens expected that the average duration of the work would be $7.7 \pm 0,36$ years, with all values above 7 years for all the sampled districts, well above the previsions of the official authorities.

In the questionnaire was included a series of items designed to measure the level of concern of the citizens on some aspects related to the various stages of the construction work. Respondents were asked to express the level of concern (on a scale from $1=$ not at all concerned and $10=$ extremely concerned) on topics such as: the increase in dust, noise and vibration, damage to homes, damage to monuments, underground water contamination, land subsidence, safety on construction sites, disruptions for city traffic. Table 2 summarizes the average recorded levels of concern, disaggregated by area of interest.

Table 2

\section{Average recorded levels of concern}

\begin{tabular}{|c|c|c|c|c|c|c|c|}
\hline & \multicolumn{2}{|c|}{ Di qua d'Arno } & \multicolumn{2}{|c|}{ Oltrarno } & \multirow[b]{2}{*}{ mean } & \multicolumn{2}{|r|}{ Total } \\
\hline & mean & $n$ & mean & $n$ & & $n$ & confidence interval \\
\hline The increase in dust & 6,7 & 1210 & 6,4 & 1210 & 6,55 & 2420 & $6,45-6,65$ \\
\hline Noise and vibration & 6,84 & 1192 & 6,57 & 1177 & 6,7 & 2369 & $6,60-6,81$ \\
\hline Damage to homes & 6,9 & 1204 & 6,73 & 1202 & 6,82 & 2406 & $6,71-6,92$ \\
\hline Damage to monuments & 6,13 & 1125 & 6,18 & 1128 & 6,15 & 2253 & $6,04-6,27$ \\
\hline $\begin{array}{l}\text { Underground water } \\
\text { contamination }\end{array}$ & 7,16 & 1189 & 7,01 & 1202 & 7,09 & 2391 & $6,99-7,19$ \\
\hline Land subsidence & 6,77 & 1083 & 6,65 & 1060 & 6,71 & 2143 & $6,60-6,82$ \\
\hline Safety on construction & 5,39 & 1034 & 5,72 & 968 & 5,55 & 2002 & $5,42-5,68$ \\
\hline
\end{tabular}


\begin{tabular}{l|ll|ll|ll|lll}
$\begin{array}{l}\text { sites } \\
\text { Disruptions for city } \\
\text { traffic }\end{array}$ & 7,45 & 1164 & 7,52 & 1177 & 7,49 & 2341 & 7,39 & $-7,59$ \\
\hline
\end{tabular}

Source: Authors

Note: on a scale from $1=$ not at all concerned and $10=$ extremely concerned; , broken down by area of interest, about topics related to the realization of the work

For almost all aspects, the average concern exceeds 6 points, except for the question about the safety in the high speed railroad construction sites $(5.55 \pm 0,13)$ which, however, appears to be the only aspect that does not directly affect the citizens. The main concern is obviously linked to the possible inconvenience due to the increase in the city traffic $(7.49 \pm 0,10)$, caused by the assumed presence of the vehicles used for the underpass construction or the expected closure of some roads. Also high is the concern for the underground water contamination $(7.09 \pm 0,10)$, probably due to the media attention given to the damages related to the high-speed railway works in the Mugello region. Strangely, there are no differences in the average levels of concern expressed by residents in the areas affected and not affected by the passage of the line.

Grouping the judgments of concern in the usual four category of scoring "not worried" (scores 1 and 2), "a little worried" (scores of 3, 4 and 5), "somewhat worried" (scores of 6, 7 and 8) and "very concerned" (scores 9 and 10), the percentage of concern for the last two bands ("somewhat" and "very ") were higher than 50\% for all issues related to the works of the construction sites. Obviously, confirming what already said for the detected average levels, the higher percentages of concern were observed for the possible inconvenience of the increase in traffic in the city $(79.3 \% \pm 1,64 \%)$ and the underground water contamination $(74.8 \% \pm 1,74 \%)$.

A second set of indicators was included in the questionnaire to measure people's expectations about the estimated impact of construction work on some factors related to the realization of the High speed lane. Respondents were asked to quantify (on a scale from 1 "maximum improvement" to 10 "maximum deterioration") their expectations on factors such as the price of train tickets, quality of local public transport on rail or rubber routes, the city's economy, livability of the area where the new station will be built, prestige and beauty of the city. For the price of the tickets and the livability of the area where the new station will be built the average expectations show a slight decrease compared to the center of the scale place at 5.50. For almost all other factors, great changes are no expected (values around the center of the scale), except for the local 
public transport by rail for which is expected to improve slightly, probably because of the information given by the media to the fact that the realization of the underground line should be able to free the surface tracks.

With regard to the opinion that the residents have on the usefulness of the project, $72 \% \pm 1,80 \%$ of respondents believe the intervention useful, although $59.2 \% \pm$ $2,32 \%$ of them $(42.6 \% \pm 1,98 \%$ of the respondents $)$ consider it too expensive. $78.9 \% \pm$ $1,62 \%$ of respondents, unfortunately, is not aware of the fact that the work will include the construction of additional measures (so-called "compensation") for the benefit of the Florentine area (e.g. the works for the hydraulic adjustment of the Mugnone creek, urban regeneration and environmental improvements, realization of new car parks, the expansion of the network of bicycle lanes, etc.) although some of them have already been implemented or are being realization.

Finally, $74.5 \% \pm 1,74 \%$ of the polled citizens expressed interest for the work in progress. The main reason for which the work is deemed deserving of attention is that this is considered to be of public interest, although not directly relate to the respondent $(61,4 \% \pm 2,64 \%) .60 .9 \% \pm 1,95 \%$ of respondents then declares he wants to be informed about the project and the development of the works. Favorite information channels are the local press, the local radio stations, the local television and the web.

\section{Conclusions}

The survey results show the level of concern for the Florentine citizen for the construction of the new high-speed rail bypass; citizens are in particular worried about the increase in the city traffic and for the possible damages to the groundwater. The major concern for the possible underground water contamination is most probably due to the emphasis given by the media to the damages happened in the Mugello Valley. Considering the opposition demonstrations promoted by local committees and the events that occurred both in Bologna and in the Mugello region, the general levels of concern measured in the city are not as high as one could imagine at first. The general level of information about the project is not very high and only $50 \%$ knows most of the details. The level of concern expressed by the respondents about the several aspects of the planned works are also related to the way the questionnaire was administered. It was frequent, for example, to find very high level of concern in people who were not aware 
of the project; a simple listing of the possible environmental damages is probably able to activate cognitive processes capable of generating states of fear. This behavior is probably due to the theory of the so-called NIMBY phenomenon that stands for "Not In My Back Yard" (Hermansson, 2007): the knowledge of the possible implementation of a great work in the vicinity of their homes activate in the citizens a spontaneous opposition process in defense of the current environment and of an idealized quality of life.

In the case of the Florentine bypass, the causes of these opposition processes are not to be found in the city's history and culture of the inhabitants as it happened in the Susa Valley where the so called "No Tav" protest movements were also due to the negative health effects of asbestos experienced in the past by the local miners of the Ambin and Musinè massifs, and are still common knowledge among the inhabitants of the Valley (Marincioni and Appiotti, 2009).

The communication policies introduced by the "Guarantee Committee for Information and Communication of the Florence High - Speed Node" tried to give more visibility to the project and to the works underway through frequent reports on the state of progress; the aim is to clarify to the citizens that the Municipality is an active agent in supervising the work with a priority interest in controlling any risk factors for residents and environment.

The survey described above was designed taking into account these purposes. These policies provide support to the hypothesis that the building of the citizens' consensus for the implementation of large public works is closely linked to the communication process of the local administration. Adequate policies of communications can efficiently reduce citizens' dreads.

The survey was conducted in May and June of 2012. However, the scientific dissemination of these results has been intentionally delayed in order to ensure to the urban policy an adequate period of reflection on the most appropriate ways to use research results because of the ongoing political debates, the extreme relevance of the issues being investigated and in the light of the fact that the drilling work has not yet started.

In January 2013, a national investigation coordinated by the Florence Public Prosecutor's office put the seal on the TBM - Tunnel Boring Machine, which was ready 
to start the excavation site in the "Campo di Marte" station. In December 2013, the TBM was unlocked but the materials for the lining of the tunnels were still seized. Two inquiries were activated: one relating to environmental crimes for the disposal of the sludge and the other for security crimes, in particular for the material used for the lining of the tunnels, which would not be as fire resistant as required by current safety standards. To date the biggest hurdle is a protocol issued by the Ministry of the Environment regarding the use of the excavated soils and stones that the TBM will produce. In December 2017 a special commission of the Ministry of the Environment evaluate positively the latest submitted plan by the contractor, after that the previous one was postponed (Min. Environment, 2016). Drilling activities should resume within the first quarter of 2018.

\section{References}

AA. VV. (2002). Impatto sul territorio delle grandi infrastrutture di trasporto: Il caso del TAV Torino-Lione, paper presented at the Seminario del Torino Social Forum sul Piano Strategico 2000-2010, Torino, 20 February 2002. Retrieved from: http://www.notavtorino.org/documenti/il-caso-tav-1a-parte.htm.

Pew Research Center (2012). Assessing the Representativeness of Public Opinion Surveys. Washington, DC: Pew Research Center.

Bowyer, B. T., \& Rogowski, J. C. (2015). Mode Matters: Evaluating Response Comparability in a Mixed-Mode Survey. Political Science Research and Methods, 1-19. https://doi.org/10.1017/psrm.2015.28.

Camera dei Deputati - XV Legislatura (2007). Ufficio Rapporti con l'Unione Europea; Progetti di finanziamento della rete trans europea di trasporto riguardanti l'Italia; Documentazione sulle politiche dell'Unione europea numero 22 del 05/12/2007. Retrieved from: http://documenti.camera.it/Leg15/Dossier/Testi/Po022.htm.

Cochran W. G. (1977). Sampling techniques (3rd edn). New York: Wiley.

Cossu R., Gadia R., \& Luria P. (2013). Environmental Impact Assessment. Retrieved from: http://147.162.77.55/VIA/dispensa_PDF. 
Bernardo, D.H., \& Curtis, A. (2013). Using online and paper surveys: The effectiveness of mixed-mode methodology for populations over 50. Research on Aging, 35 (2), 220240. doi: 10.1177/01640275124416.

De Leeuw E. D. (2005). To mix or not to mix data collection modes in surveys. Journal of Official Statistics, 21, 2: 233-255 Retrieved from: http://www.jos.nu/Articles/abstract.asp?article=212233.

De Leeuw E. D., Hox J. J., \& Dillman D. A. (2008). International handbook of survey methodology. European Association of Methodology Series, New York: Lawrence Erlbaum Associates.

Douglas M., \& Wildavsky A. (1982). Risk and culture: An essay on the selection of Technical and Environmental Dangers. Berkeley: University of California Press.

Douglas M. (1992). Risk and Blame: Essays in Cultural Theory. London: Routledge.

European Commission (2013). Infrastructure - TEN-T - Connecting Europe. Retrieved from: http://ec.europa.eu/transport/wcm/video/VP_Kallas_CoreNetworkCorridors.mp4.

Gray P. C. R., \& Wiedemann P. M. (1999). Risk management and sustainable development: mutual lessons from approaches to the use of indicators. Journal of Risk Research, 2(3), 201-218.

Hermansson H. (2007). The ethics of NIMBY conflicts. Ethic Theory Moral Practice 10(1) 23-34.

Kasperson, R. E., Renn, O., Slovic, P., Brown, H. S., Emel, J., Goble, R., ... Ratick, S. (1988), The Social Amplification of Risk: A Conceptual Framework. Risk Analysis, 8: 177-187. doi:10.1111/j.1539-6924.1988.tb01168.x.

Kays K., Keith T. L., \& Broughal M. T. (2013). Best Practice in Online Survey Research with Sensitive Topics. In Sappleton N.: Advancing Research Methods with New Technologies. IGI Global, 157-168. doi:10.4018/978-1-4666-3918-8.ch009.

Leiss W. (1996). Three phases in the evolution of risk communication practice. The Annals of the American Academy of Political and Social Science, 545, 85-94. doi.org/10.1177/0002716296545001009.

Lupton D. (1999). Risk. New York: Routledge. 
Maccheri M., Monaci Naldini D., \& Antompaoli M. L. (2003). Relazione sulle ricerche di Amianto nella Bassa Val di Susa, lungo il tracciato del progetto preliminare del nodo urbano di Torino, potenziamento linea Bussoleno-Torino e cintura merci. Siena: Centro di Geotecniche dell'Università di Siena.

Marincioni F., \& Appiotti F. (2009). The Lyon-Turin High-Speed Rail: The Public Debate and Perception of Environmental Risk in Susa Valley, Italy. Environmental Management, 43, 863-875. Doi:10.1007/s00267-009-9271-2.

Min. Ambiente (2016). Comunicati Stampa. http://www.minambiente.it/comunicati/tavfirenze-riutilizzo-di-terre-e-rocce-da-scavo-servira-nuovo-put.

Pheland P., \& Reynolds P. (1996). Argument and evidence, critical analysis for the social sciences. London: Routledge.

Ruggiero V. (2000). Movimenti nella città. Torino: Bollati-Borighieri.

Sarndal C. E., Swensson B., \& Wretman J. (1992). Model Assisted Survey Sampling. New York: Springer-Verlag.

Sidhu K. S. (2005). New Approaches to Measurement and Evaluation. New Delhi: Sterling Publishers Pvt. Ltd.

Slovic P. (2000). The Perception of Risk. London: Earthscan Publications Ltd.

\section{Prof. Bruno Bertaccini, PhD}

Dept. of Statistics, Informatics, Applications "G. Parenti" of the University of Florence v.le Morgagni, 59, 50134 - Italy

www.disia.unifi.it

bruno.bertaccini@unifi.it

Bruno Bertaccini research interests involve the evaluation of teaching policies and, more in general, the evaluation of public services. He is also expert in the design and development of (web based) statistical information systems. He carries out regular teaching activity in first level and second level degree and master courses. He is the author and co-author of monographs and many scientific articles in national and international journals.

\section{Giulia Biagi, PhD}

Dept. of Statistics, Informatics, Applications "G. Parenti" of the University of Florence v.le Morgagni, 59, 50134 - Italy

www.disia.unifi.it 
biagi@disia.unifi.it

Giulia Biagi graduated in Business Economics at the Faculty of Economics and got a $\mathrm{PhD}$ in Applied Statistics at the Dept. of Statistics of the University of Florence at the University of Florence. She is a Postdoctoral Researcher since 2014. Her research interests involve the evaluation the evaluation of public services. She is also expert in the design and management of opinion polls and surveys. She is co-author of scientific articles in national and international journals. 